\title{
Designing Passive Harmonic Filter on Dynamic Positioning Vessel's Electrical System Affected using Electrical Thruster
}

\author{
Sardono Sarwito ${ }^{1}$, Indra Ranu Kusuma ${ }^{2}$, Yose Gregory Tarigan ${ }^{3}$
}

(Received: 02 August 2018 / Revised: 23 March 2019 / Accepted: 28 September 2019)

\begin{abstract}
To be able to maintain the position, generally ship with dynamic positioning system have several thruster located at bow or stern of the ship. Based on the propulsion system, there are 2 types of thruster which is mechanical thruster and electrical thruster. In electrical type, thruster is driven by an electric motor supplied from the generator. In addition, on dynamic positioning vessel equipped with electrical thruster, there are also VFD or Variable Frequency Drive to control the speed of motor thruster. The use of VFD components in the system may cause harmonic interference. Harmonic itself can be regarded as distortion in the sinusoidal waves due to the interference of other waves that have integer frequency multiples of their fundamental frequency due to the operation of non-linear thruster motor. Some of the most affected components of this distortion are the communications equipment and the components used for measurement. This research conducted an analysis of harmonic disturbance arising from the operation of 2 units bow thruster on DP Ship by simulating 6 scenario of generator configuration using simulation software. The results from this research were total harmonic distortion value or VTHD of the system that comply with standards and rules, also specification of passive harmonic filter to reduce the VTHD value at the specific harmonic order.
\end{abstract}

Keywords — dynamic positioning, generator configuration, harmonic distortion, total harmonic distortion value, variable frequency drive.

\section{INTRODUCTION}

$\mathrm{D}$ ynamic positioning vessels have the ability to maintain its position dynamically against 6 degree of movement such as yaw, surge, heave, pitch and roll. This type of ship equipped with thrusters other than the main propulsion that located at the bow or stern of the ship. There are 2 types of thrusters based on its propulsion system such as mechanical thrusters and electrical thrusters. On a DP Ship with electric thrusters, the largest electrical load is generally found on the thrusters motor. There are 2 mode of generator configuration that generally applied on DP Vessel to supply electrical power for thrusters such as open bus mode and close bus mode. Generally DP Vessel operated with open bus configuration to increase redundancy and prevent loss of DP Capability. But using open bus means increasing investment cost of generator and may increase exhaust gas emission from operating more generator [5].

For thrusters that use a 3-phase induction motor as a driver, there is also a component named VFD as known as Variable Frequency Drive to control the speed of the motor. VFD is one of non linear load where the current wave or voltage output is not equal to the input wave. Non-linear load on the system result in the emergence of harmonics disturbance [7]. Harmonic itself can be regarded as distortion in the sinusoidal waves due to the interference of other waves that have integer frequency

Sardono Sarwito, Departement of Marine Engineering, Institut Teknologi Sepuluh Nopember, Surabaya, 60111, Indonesia. E-mail: sarsar@its.ac.id

Indra Ranu Kusuma, Departement of Marine Engineering, Institut Teknologi Sepuluh Nopember, Surabaya, 60111, Indonesia. E-mail: irkusuma97@gmail.com

Yose Grgeory Tarigan, Departement of Marine Engineering, Institut Teknologi Sepuluh Nopember, Surabaya, 60111, Indonesia. E-mail: - multiples of their fundamental frequency. Harmonic on electrical system may affect other electrical component, some of the most affected are the communications equipment and component for measurement if the harmonic value is beyond the limit. Value of harmonic distortion may be dampened to a value within safe limits. One of method to reduce harmonic value is to install passive harmonic filter on electrical system after obtaining harmonic distortion value on the ship's electrical system. On this research, values of harmonic distortion are obtained by doing harmonic analysis simulation on software. Mitigation of harmonic distortion is done after highest value of total harmonic distortion that exceed IEEE and ABS limit obtained. After passive harmonic filter installed, then the harmonic analysis simulation is done again on the electrical system to know the ability of the filter to reduce harmonic distortion value below limits.

\section{A. Dynamic Positioning}

Dynamic Positioning is a way of holding the ship in a relatively unchanged position with seafloor as a refrence point, without using anchor but using 2 or more propulsion [7]. Ship with dynamic positioning systems are classified into 3 classes, the highest class is equipment class 3 where there is a separation of its equipment to prevent flood or fire in one compartement [6].

There are many new ship with DP system built for offshore supply vessel have use diesel-electric thruster. Reduction of fuel consumption and emision from dieselelectric thruster is more significant than conventional 
thruster, where thruster powered from a diesel engine for intermitten operational condition. Based on paper published by ABB AS, 30\%-40\% fuel saving occur on ship with diesel electric thruster [1].

\section{B. Harmonic Disturbance on Ship Electrical\& Effect}

Harmonics can be regarded as a defect in the sinusoidal waves due to interference of other waves that have an integer multiple frequency of its fundamental frequency. This harmonic frequency can result in the fundamental frequency or frequency from sinusoidal wave in system become distorted [5].

Generally harmonic frequencies are integer multiplies (e.g. 3,5,7,11,13,15, etc) of its fundamental frequency (Satrio, 2014). In an AC Voltage system with a fundamental frequency of $50 \mathrm{~Hz}$ AC voltage, with 7th harmonic wave generates wave with frequency of $350 \mathrm{~Hz}$ and at 11 th harmonic wave generates wave with frequency of $550 \mathrm{~Hz}$. The frequency of harmonics in each order if summed will cause the distorted wave form of sinusoidal wave or fundamental wave. Figure 1 shows example of distorted wave form beacuse of 3rd harmonic and 5th harmonic.

The existence of harmonics in a power system can give effect directly or indirectly to the quality of the system. In electric power distribution system, harmonic flow can decrease power quality. The distortion in the current waveform and the input voltage can result as follow [1]:

- Acceleration of Aging Insulation Material

- Excess burden on Electronic Equipment

- Malfunctions of Electronic Equipment

\section{Total Harmonic Distortion Standard}

To find if the system is distorted by harmonics or not, it can be seen from the value of voltage total harmonic distortion. The value of THD is comparison between the frequency value of the harmonic frequency and the value at its fundamental frequency. The maximum value of THD is regulated on IEEE 519-2019 and also ABS Classifiaction Rules ABS Part 4 Chapter 8 Section 2. Table 1 are the limit that regulated by IEEE.

\section{Passive Harmonic Filter}

Harmonic filter is installed to reduce the amplitude one or more harmonic frequencies of voltage and current. Installation of this filter on the electrical system serves to reduce the propagation harmonic current throughout the network. In addition, installation of filters can also provide reactive power compensation at fundamental frequencies, resulting in power factor improvement in the system [2].

Passive harmonic filster is a combination of the inductor, resistor and capacitor components. The inductance and capacitance from passive harmonic filter are designed to resonate at certain frequencies, so if there is harmonics with the same frequency as resonant frequency, then the passive filter will absorb the harmonics, so the harmonics are not affected into system or at least safe to the system [8].

The use of this filter aims to minimize the harmonic value and not to eliminate it completely. In this research calculation of specification of capacitor and inductor will be done on simulation software. Type of passive harmonic filter that will be designed on this research is single tuned filter type. This type of passive harmonic filter will tuned into one of the harmonic order. Single tuned filter consist of capasitors, inductor and resistor in series [8]. Figure 2 shows the single tuned filter circuit.

\section{E. Variable Frequency Drive}

To be able controlling speed of an a 3-phase AC induction motor, system needs a component named Variable Frequency Drive. VFD is a power electronics equipment to control motor rotation speed. VFD consists of a 3 phase converter. This equipment works is changing the AC 3 phase voltage from input side into DC Voltage using 3 phase rectifier. The DC Voltage will then supplied to a 3 phase inverter to convert into 3 phase AC Voltage with frequency which can be controlled as needed. In this research VFD are the source of harmonic load because of non-linear load that this equipment generates [8]. Figure 3 depicts the VFD circuit.

\section{METHOD}

\section{A. Problem Statement}

In this stage the reason why an existing problem must be solved. Problem search is done by exploring information about the problems that occur on the ship with dynamic positioning system. From this stage, purpose of this research also can be found. In this research, the problem that will be discussed and solved is the harmonic distortion value, the impact and design of the filter to reduce value of harmonic distortion in the electrical system of ship using dynamic positioning system.

\section{B. Literature Study}

The study of literature is the stage to find the theories used as reference in designing system and reference in doing simulation.

\section{Data Collecting}

At this stage conducted data collecting in the form of information as follows:

- Single Line Diagram of Ship's Electrical System

- Electrical Load When Operating Dynamic Positioning

- Component Specification of Ship's

- IEEE and ABS Rules and Standard

\section{Harmonic Simulation and Analysis Without \\ Harmonic Filter}

At this stage ship's electrical system will be re drawn at software simulation. After that harmonic analysis simulation conducted to obtain data of voltage harmonic distortion in the system. Data obtained from this stage such as VTHD and VIHD that exceed limits standards will be used as reference to design passive harmonic filters.

\section{E. Validation I}

At this stage will be analyzed from simulation data which condition are generating highest harmonic distortion value then it will be compared with the IEEE and ABS limits standard if the result is exceeding or not. In the configuration and variation that generate harmonic distortion value below limits, simulation using passive harmonic filter will be determined too. 
International Journal of Marine Engineering Innovation and Research, Vol. 4(2), Sept. 2019. 87-95 (pISSN: 2541-5972, eISSN: 2548-1479)

\section{F. Passive Filter Modeling}

After obtaining the simulation results, then installing passive harmonic filter at bus-bar $\mathrm{D}$ and $\mathrm{E}$ which is connected to source of harmonic such as Variable
Frequency Drive. Installing passive harmonic filter were done by connecting passive harmonic filter component from drawing menu to the bus-bar. Figure 4 shows symbol of passive harmonic component on simulation software.
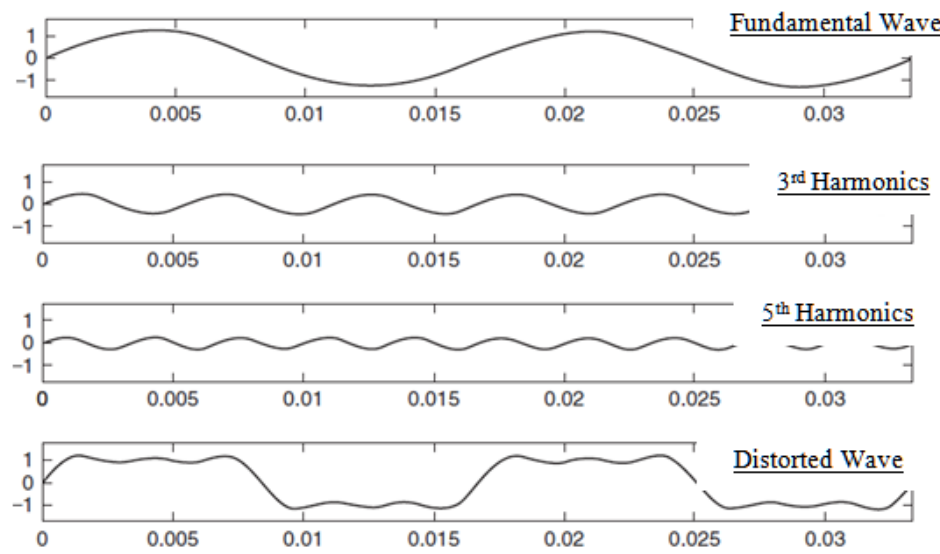

Figure. 1. VHTD before filter installation

TABLE 1.

VHTD BEFORE FILTER INSTALLATION

Bus voltage V at PCC $\quad$ Individual harmonic (\%) $\quad$ Total harmonic distortion THD (\%)

\begin{tabular}{lll}
\hline$V \leq 1.0 \mathrm{kV}$ & 5.0 & 8.0 \\
$1.0 \mathrm{kV}<V \leq 69 \mathrm{kV}$ & 3.0 & 5.0 \\
$69 \mathrm{kV}<V \leq 161 \mathrm{kV}$ & 1.5 & 2.5 \\
$161 \mathrm{kV}<V$ & 1.0 & 1.5 \\
\hline
\end{tabular}

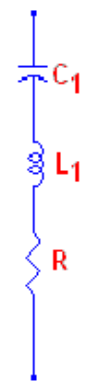

Figure. 2. Single tuned harmonic filter circuit

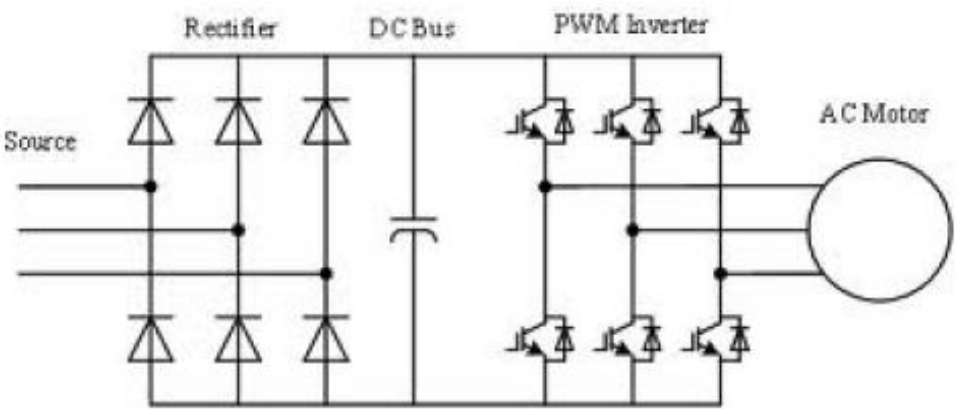

Figure. 3. VFD circuit

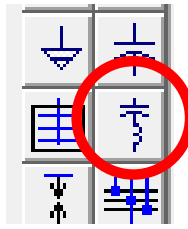

Figure. 4. Harmonic filter symbol in software simulation 
TABLE 2.

\begin{tabular}{lcccc}
\multicolumn{5}{c}{ HARMONIC ORDER TUNING } \\
Order & $5^{\text {th }}$ & $7^{\text {th }}$ & 9 th & 11 th \\
Tuning & 4.813 & 6.734 & 8.663 & 10.59 \\
Order & $13^{\text {th }}$ & 15 th & 17 th & 19 th \\
& & & 16.36 & 18.29 \\
Tuning & 12.51 & 14.44 & \\
\hline
\end{tabular}

After filter have been installed at the system, then from simulation result determine the highest harmonic order that will be used for tuning harmonic filter. In designing passive harmonic filter in simulation software need to determine few design parameter such as follows:

- Harmonic Order, this parameter is the order tuning value of the harmonic distortion at the highest harmonic order that will be reduce by the filter [3]. Value used in tuning order is shown in the Table 2.

- Harmonic Current, this value is found at cable that connected to VFD and obtained from harmonic analysis simulation

- PF Correction, passive harmonic filter consists of a series of inductors and capacitors so beside reducing harmonic value, can also used to improve value of power factor. Existing PF Value obtained from load flow analysis simulation

- Load MVA, this value is power that loaded at cable that connect VFD to busbar and obtained from load flow analysis

- Q Factor, this value serves as a value to determine the sharpness of the ability of the filter to reduce harmonic order that has been tuned on the data harmonic order above [3]. Table 3 shows comparison of filter absorption capability at 5 th and 7 th order:

\section{G. Harmonic Simulation and Analysis With Harmonic Filter}

Furthermore, after designing and finding size and type of filter based on initial simulation data, then doing simulation again with filter installed on the electrical system. This is done to see whether the design of passive harmonic filter can reduce harmonics and distortion for later would be compared with previous simulation resuts.

\section{H. Validation II}

At this stage will be analyzed whether the design results of this passive harmonic filter can reduce harmonics and distortion in accordance with existing rules and standards. If the simulation results after installed filter still having above standard limits, passive harmonic filter will be redesigned until the value reduced below the standard

\section{Conclusion}

The final step in this research is to make conclusion of the whole process that has been done before and provide answers to the problem that stated before. Suggestion are given based on the results of the analysis and can be used as reference for further research, either directly related to this research or on the data and methodology that will be referenced later.

\section{RESULTS AND DISCUSSION}

\section{A. Ship's Principal Dimension}

The ship used as the object of this research is a ship with dynamic positioning system where there are 2 units of bow thruster to maintain position of the ship dynamically as the largest non-linear load source on the ship's electrical system. This ship is an Anchor Handling and Tug Supply Type ship that has a function to provide supply needs in offshore structure, performing anchoring jobs and others that require ability to maintain heading and position of the ship. Table 4 gives information about ship principals.

\section{B. Ship's Single Line Diagram}

To be able to simulate harmonic in a software simulation, the one of the most important data needed is the single line diagram data on the ship's electrical system. Single line diagram itself is an electrical schematic of the ship's electrical system that shows which components are connected to the bus and how big the power and other specification of each component and so on. Single line diagram drawn on software by dragging electrical component on edit menu, then connecting all component via cable and bus-bar. After component placed on worksheet and connected each others, then specification of all components are filled in accordance with ship's specification data. The single line diagram is in Figure5.

\section{Scenario of Generator Configuration}

The simulation on this research will be varied based on generator configuration scenarios and thruster load variation that thruster operated varies from $20 \%$ to $100 \%$ of maximum power motor.

\section{Harmonic Simulation Before Filter Installed}

After single line diagram of ship's electrical system have been drawn, and configuration of each scenario have been determined, then simulation of harmonic can be done by using harmonic analysis menu on software simulation. Simulation done on 6 scenarios above with 5 variations of operated motor power. Values that will be obtained from this simulation are voltage total harmonic distortion value and individual harmonic distortion value for every order on main busbar. Purpose of this step are to know how much harmonic distortion happened on ship's electrical system and to know if it's exceed the limits given by IEEE and ABS Classification Rules. All the VTHD and VIHD are in mag (\%) unit. Mag (\%) unit represent the magnitude of the ratio between the current/voltage value with the fundamental current/voltage [7]. From simulation results table 5 above, harmonic distortion occurs from the motor operating at $20 \%$ of rated power but the value of total harmonic distortion that occurs at that power is still acceptable by ABS rules. VTHD value generally starts exceeding IEEE limits and ABS limits from Variation B where 2 thruster operated at $50 \%$ of its rated power each. From table above we know that generator configuration that having highest VTHD value is generator 
configuration scenario 6 , where in variation D the VTHD value having mag $23 \%$ and the limits given by IEEE and $\mathrm{ABS}$ is $8 \%$ for voltage total harmonic distortion value. In scenario 3 variation C, D and E can't be done because at this configuration, power that supplied by shaft generator to thruster is not sufficient to operate at $70 \%$ of motor thruster rated power.

\section{E. Filter Specification}

After the harmonic values that exceed IEEE and ABS Standards are obtained, then performed mitigation to the system by installing passive harmonic filter on the bus-bar where the source of harmonics are connected, in this research, the source of harmonics is variable frequency drive. The design of harmonic filter in this research is done on software simulation and with filter specification value done according to the largest order of harmonics distortion.

Largest voltage individual harmonic distortion obtained from the simulation above are mostly found in the 5th orders harmonics so that the passive harmonic filter will be tuned at 5 th harmonics order.

TABLE 3.

Q FACTOR PERCENTAGE ON $5^{\mathrm{TH}}$ AND $7^{\mathrm{TH}}$ HARMONIC ORDER

\begin{tabular}{lllllll}
\hline Filter & $\mathbf{Q}_{\mathbf{5}}(\boldsymbol{\%})$ & $\mathbf{Q}_{\mathbf{1 0}}(\boldsymbol{\%})$ & $\mathbf{Q}_{\mathbf{3 0}}(\boldsymbol{\%})$ & $\mathbf{Q}_{\mathbf{5 0}}(\boldsymbol{\%})$ & $\mathbf{Q}_{\mathbf{7 0}}(\boldsymbol{\%})$ & $\mathbf{Q}_{\mathbf{1 0 0}}(\boldsymbol{\%})$ \\
\hline 5th & 28.6 & 51.2 & 87.28 & 94.48 & 97.98 & 98.66 \\
7th & 38.54 & 64.12 & 92.90 & 97.98 & 98.58 & 99.38 \\
\hline
\end{tabular}

TABLE 4

SHIP'S PRINCIPAL DIMENSION.

\begin{tabular}{ll}
\hline \multicolumn{2}{c}{ Ship's Principal Dimension } \\
\hline L.O.A & $59.250 \mathrm{~m}$ \\
L.W.L & $56 \mathrm{~m}$ \\
L.P.P & $52.2 \mathrm{~m}$ \\
Beam Moulded & $14.950 \mathrm{~m}$ \\
Depth Moulded & $6.1 \mathrm{~m}$ \\
Draft & $4.950 \mathrm{~m}$ \\
DP Equipment Class & DP Class 1
\end{tabular}

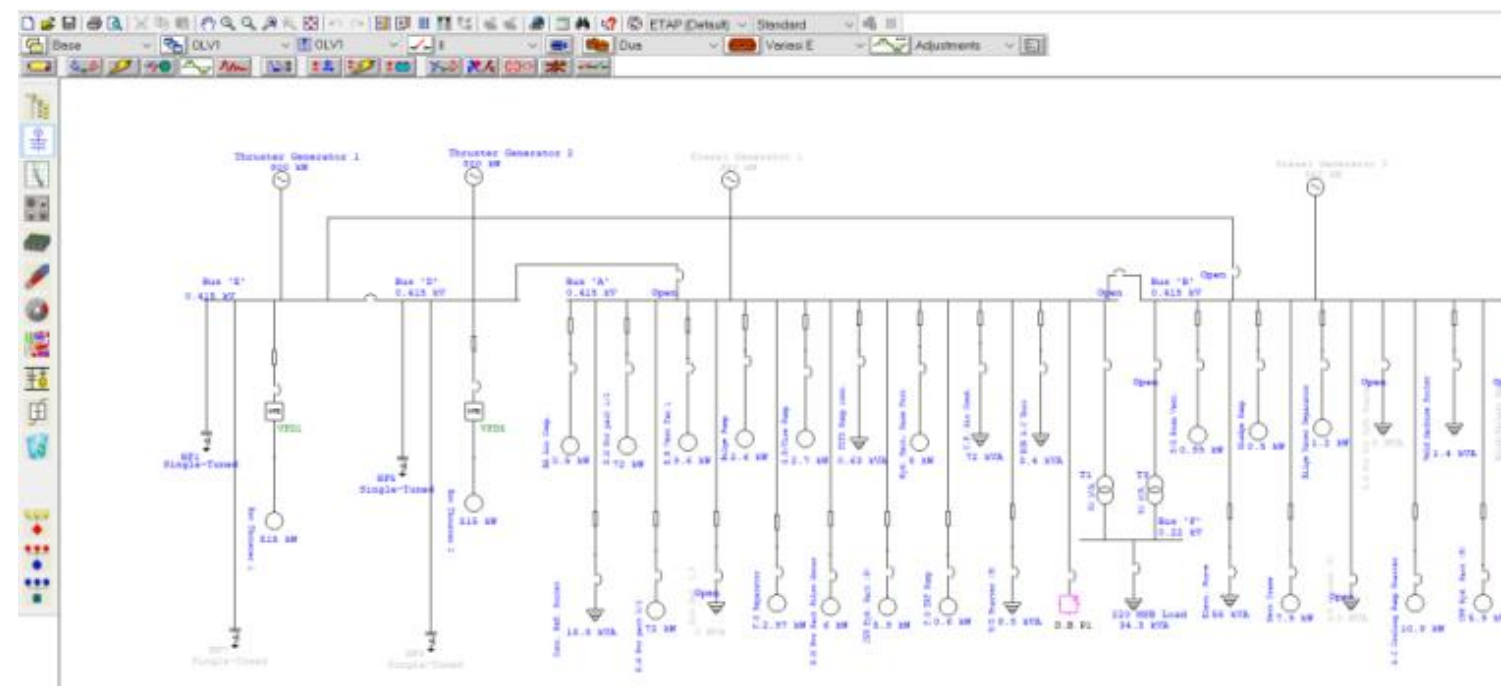

Figure. 5. Ship's single line diagram 
International Journal of Marine Engineering Innovation and Research, Vol. 4(2), Sept. 2019. 87-95 (pISSN: 2541-5972, eISSN: 2548-1479)

TABLE 5.

VHTD BEFORE FILTER INSTALLATION.

\begin{tabular}{|c|c|c|c|c|c|c|c|c|c|c|}
\hline \multicolumn{11}{|c|}{ Voltage Total Harmonic Distortion (\%) } \\
\hline \multirow{2}{*}{$\begin{array}{c}\text { Generator } \\
\text { Configuration }\end{array}$} & \multicolumn{2}{|c|}{$\begin{array}{l}\text { Variation } A \\
(20 \%-20 \%) \\
\end{array}$} & \multicolumn{2}{|c|}{$\begin{array}{r}\text { Variation B } \\
(50 \%-50 \%) \\
\end{array}$} & \multicolumn{2}{|c|}{$\begin{array}{l}\text { Variation C } \\
(70 \%-70 \%) \\
\end{array}$} & \multicolumn{2}{|c|}{$\begin{array}{c}\text { Variation D } \\
(100 \%-100 \%)\end{array}$} & \multicolumn{2}{|c|}{$\begin{array}{l}\text { Variation E } \\
(70 \%-40 \%) \\
\end{array}$} \\
\hline & $\begin{array}{c}\text { no } \\
\text { filter }\end{array}$ & filter & $\begin{array}{c}\text { no } \\
\text { filter }\end{array}$ & filter & $\begin{array}{c}\text { no } \\
\text { filter }\end{array}$ & filter & no filter & filter & $\begin{array}{c}\text { no } \\
\text { filter }\end{array}$ & filter \\
\hline Scenario 1 & 4.57 & 2.05 & 11.45 & 5.14 & 16.05 & 7.21 & 22.98 & 6.35 & $\mathbf{x}$ & $\mathbf{x}$ \\
\hline Scenario 2 & 4.57 & 2.05 & 11.45 & 5.14 & 16.05 & 7.21 & 22.98 & 6.35 & 12.6 & 5.66 \\
\hline Scenario 3 & 7.54 & 2.76 & 18.9 & 6.93 & $\mathbf{x}$ & $\mathbf{x}$ & $\mathbf{x}$ & $\mathbf{x}$ & $\mathbf{x}$ & $\mathbf{x}$ \\
\hline Scenario 4 & 3.54 & 1.73 & 8.87 & 4.34 & 12.44 & 6.08 & 17.82 & 5.76 & 9.77 & 4.78 \\
\hline Scenario 5 & 3.13 & 1.45 & 7.83 & 3.99 & 10.98 & 5.59 & 15.72 & 5.47 & 8.62 & 4.39 \\
\hline Scenario 6 & 4.63 & 2.06 & 11.61 & 5.18 & 16.27 & 7.26 & 23.3 & 6.38 & 12.78 & 5.7 \\
\hline
\end{tabular}

TABLE 6.

SPECIFICATION OF PASSIVE HARMONIC FILTER $5^{\text {TH }}$ HARMONICS ORDER

\begin{tabular}{llcl}
\hline Scenario & Configuration & Generator Power $(\mathbf{k W})$ & Load $(\mathbf{k W})$ \\
& & & \\
Scenario 1 & Only bow thruster as a load & \\
Scenario 2 & 2 SG $=2$ BT & 800 & 515 \\
Scenario 3 & 1 SG = 2 BT & 1600 & 1030 \\
& & 800 & 515 \\
Scenario 4 & 1 DG \& 2 SG = 2 BT \& load & Bow thruster and electricity as load & \\
Scenario 5 & 2 DG \& 2 SG = 2 BT \& load & 1950 & 1434.387 \\
Scenario 6 & 2 DG \& 1 SG = 2 BT \& essential load & 2300 & 1434.387 \\
\hline
\end{tabular}

TABLE 7.

SPECIFICATION OF PASSIVE HARMONIC FILTER $5^{\text {TH }}$ HARMONICS ORDER

\begin{tabular}{cc}
\hline Passive Harmonic Filter 5th Order Specification \\
\hline Q Factor & 45 \\
Harmonic Order & 4.81 \\
Harmonic Current & 88.96 \\
Load MVA & 0.602 \\
Rated kV & $0.415 \mathrm{kV}$ \\
Capacitor Size (kVar) & $107 \mathrm{kVar}$ \\
Capacitor Size (farrad) & $1970 \mathrm{mF}$ \\
Inductor Size & $0.0698 \mathrm{H}$ \\
\hline
\end{tabular}

TABLE 8.

SPECIFICATION OF PASSIVE HARMONIC FILTER $5^{\text {TH }}$ HARMONICS ORDER WITH DIFFERENT HARMONIC ORDER

\begin{tabular}{cc}
\hline Passive Harmonic Filter 7th Order Specification \\
\hline Q Factor & 45 \\
Harmonic Order & 6.73 \\
Harmonic Current & 88.96 \\
Load MVA & 0.602 \\
Rated kV & 0.415 \\
Capacitor Size (kVar) & $107 \mathrm{kVar}$ \\
Capacitor Size (farrad) & $1970 \mathrm{mF}$ \\
Inductor Size & $0.0357 \mathrm{H}$ \\
\hline
\end{tabular}




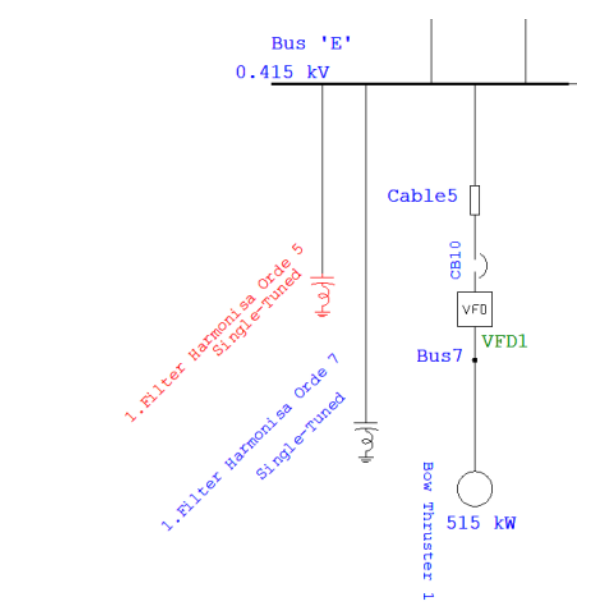

Figure. 6. Installed passive harmonic filter on ship's SLD

TABLE. 9.

VHTD DISTORTION BEFORE AND AFTER FILTER INSTALLATION

\begin{tabular}{|c|c|c|c|c|c|c|c|c|c|c|}
\hline \multicolumn{11}{|c|}{ Voltage Total Harmonic Distortion (\%) } \\
\hline \multirow{2}{*}{$\begin{array}{l}\text { Generator } \\
\text { Configuration }\end{array}$} & \multicolumn{2}{|c|}{$\begin{array}{l}\text { Variation A } \\
(20 \%-20 \%) \\
\end{array}$} & \multicolumn{2}{|c|}{$\begin{array}{l}\text { Variation B } \\
(50 \%-50 \%) \\
\end{array}$} & \multicolumn{2}{|c|}{$\begin{array}{l}\text { Variation C } \\
(\mathbf{7 0 \%}-70 \%) \\
\end{array}$} & \multicolumn{2}{|c|}{$\begin{array}{c}\text { Variation D } \\
(100 \%-100 \%)\end{array}$} & \multicolumn{2}{|c|}{$\begin{array}{l}\text { Variation E } \\
(70 \%-40 \%)\end{array}$} \\
\hline & $\begin{array}{c}\text { no } \\
\text { filter }\end{array}$ & filter & $\begin{array}{c}\text { no } \\
\text { filter }\end{array}$ & filter & $\begin{array}{c}\text { no } \\
\text { filter }\end{array}$ & filter & no filter & filter & $\begin{array}{c}\text { no } \\
\text { filter }\end{array}$ & filter \\
\hline Scenario 1 & 4.57 & 2.05 & 11.45 & 5.14 & 16.05 & 7.21 & 22.98 & 6.35 & $\mathbf{x}$ & $\mathbf{x}$ \\
\hline Scenario 2 & 4.57 & 2.05 & 11.45 & 5.14 & 16.05 & 7.21 & 22.98 & 6.35 & 12.6 & 5.66 \\
\hline Scenario 3 & 7.54 & 2.76 & 18.9 & 6.93 & $\mathbf{x}$ & $\mathbf{x}$ & $\mathbf{x}$ & $\mathbf{x}$ & $\mathbf{x}$ & $\mathbf{x}$ \\
\hline Scenario 4 & 3.54 & 1.73 & 8.87 & 4.34 & 12.44 & 6.08 & 17.82 & 5.76 & 9.77 & 4.78 \\
\hline Scenario 5 & 3.13 & 1.45 & 7.83 & 3.99 & 10.98 & 5.59 & 15.72 & 5.47 & 8.62 & 4.39 \\
\hline Scenario 6 & 4.63 & 2.06 & 11.61 & 5.18 & 16.27 & 7.26 & 23.3 & 6.38 & 12.78 & 5.7 \\
\hline
\end{tabular}

In scenario 1 Variation $B$, the value of VIHD at 5 th harmonic order have the highest value before passive harmonic filter was installed. But after mitigation of harmonics with installing passive harmonic filters, the VIHD value of all order at bus-bar D and E significanly reduced from $8.88 \%$ to the $1.56 \%$ of VIHD 5 th harmonic order value as seen on Figure 7.

In scenario 2 Variation $\mathrm{B}$, the VIHD 5th harmonic order value reduced as much as $7 \%$ become $1.56 \%$ and also others harmonics order are reduced as shown Figure 8. In scenario 3 Variation B, the VIHD value of all order at bus-bar D and E reduced such as $12.98 \%$ reduction to the $1.68 \%$ of VIHD 5th harmonic order value as seen on Figure 9.

From simulation of scenario 4 results, the VIHD value of all order at bus-bar D and E significanly reduced from $7 \%$ to the $1.49 \%$ of VIHD 5 th harmonic order value as seen on Figure 10.

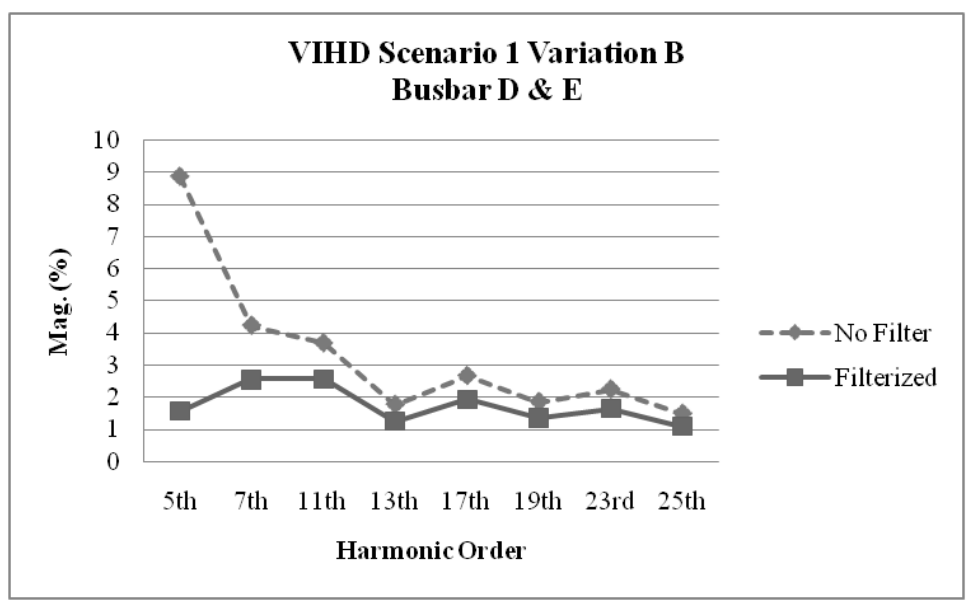

Figure. 7. VIHD of Variation B Scenario 1. 
International Journal of Marine Engineering Innovation and Research, Vol. 4(2), Sept. 2019. 87-95 (pISSN: 2541-5972, eISSN: 2548-1479)

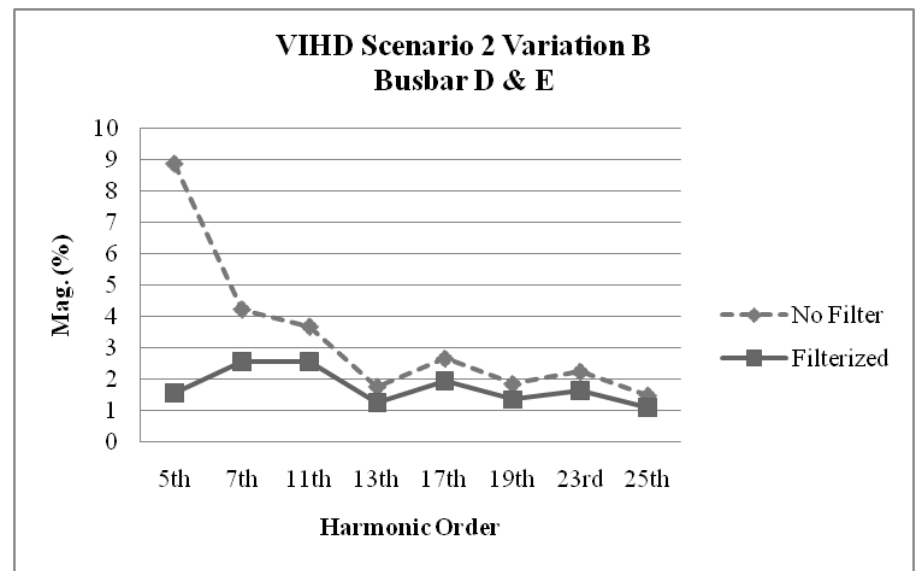

Figure. 8. VIHD of Variation B Scenario 2.

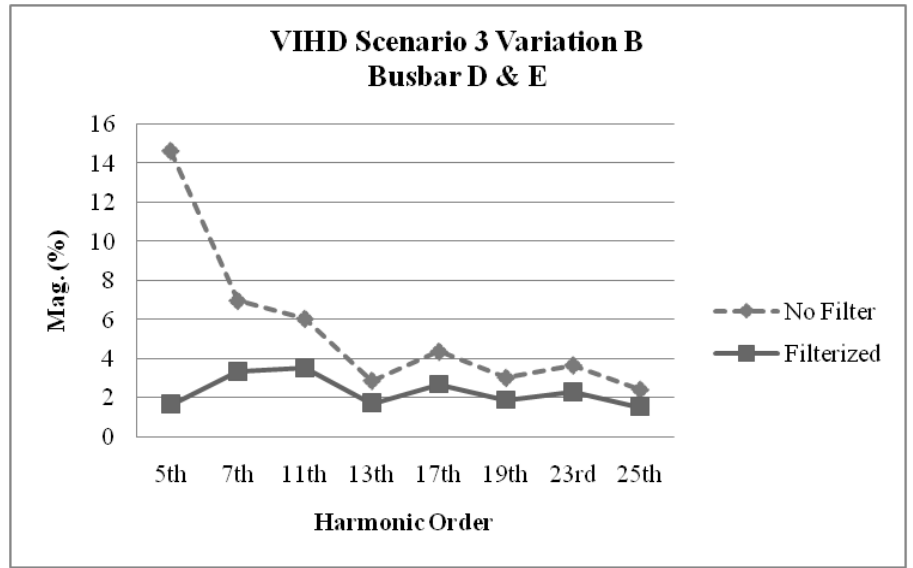

Figure. 9. VIHD of Variation B Scenario 3.

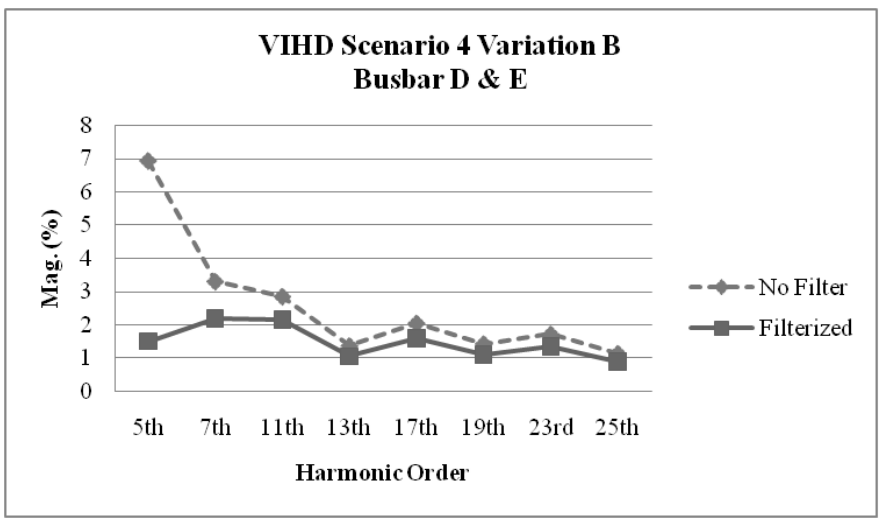

Figure. 10. VIHD of Variation B Scenario 4.

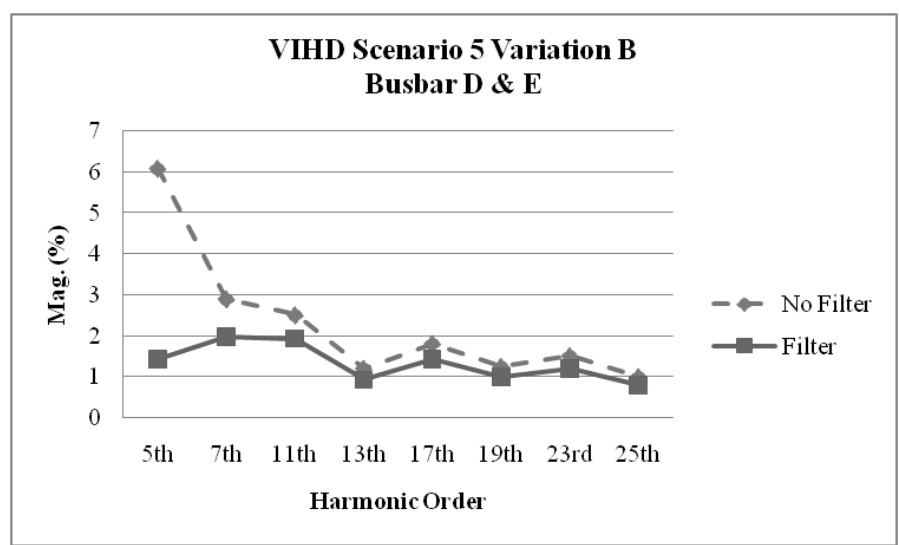

Figure. 11. VIHD of Variation B Scenario 5. 


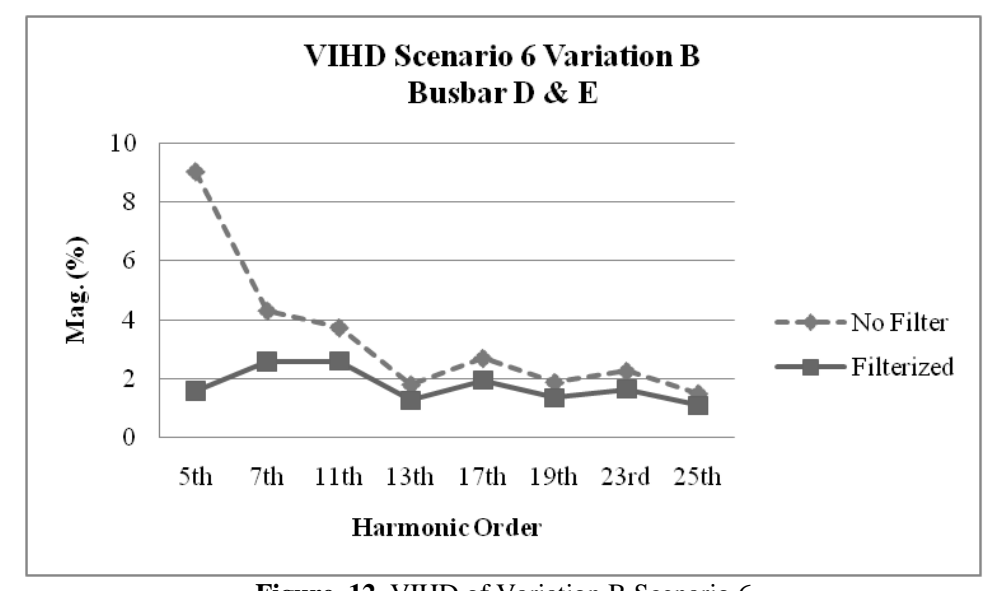

Figure. 12. VIHD of Variation B Scenario 6

In scenario 5 Variation $\mathrm{B}$, the value of VIHD at 5 th harmonic order have the highest value before passive harmonic filter was installed. But after mitigation of harmonics with installing passive harmonic filters, the VIHD value of all order at bus-bar D and E reduced such as $4 \%$ reduction to the $1.44 \%$ of VIHD 5 th harmonic order value as seen on Figure 11.

In scenario 6 Variation $B$, the value of VIHD at 5th harmonic order at bus-bar D and $\mathrm{E}$ have the highest value before passive harmonic filter was installed. But after mitigation of harmonics by installing passive harmonic filters, the VIHD 5th harmonic order value reduced as much as $7.5 \%$ become $1.57 \%$ and also others harmonics order are reduced as shown on Figure 12.

\section{CONCLUSION}

After the simulation of harmonics analysis on DP Ship's Electrical System with 6 configuration of genereator using software simulation, can be concluded as follow:

1. From the simulation results, for the variation of $A$ to $\mathrm{C}$, harmonics value generated on the system can be reduced using 5 th harmonic order tuned filter for each bus, but the variation D when thruster motor operated at its rated power requires addition of 7 th harmonic order tuned filter to reduce VTHD on this variation.

2. After passive harmonic filter installed on the system, value of VTHD and VIHD obtained decreased significanly before filter was installed. Although there are still have VTHD and VIHD values in the system but these value are within the limits set by IEEE and
ABS.

From the simulation results, it can be concluded that in the same operational thruster variation, scenario 4,5 and 6 which the generator are paralled have smaller VTHD value compared to others that its generator separated from main generator. This means it is possible to operate thruster in paralel generator configuration even though harmonic distortion found on the system but it can be reduced by using passive harmonic filter.

\section{REFERENCES}

[1] Adnanes, Alf Kare. Maritime Electrical Installation and Diesel Electrical Propulsion. Oslo: ABB AS, 2003.

[2] Arifin, Arie, Margo Pujiantara, and Arif Mustofa. "Perancangan Filter dengan Metode Multistage Passive Filter pada Proyek Pakistan Deep Water Container Port." Teknik Elektro FTI-ITS. Surabaya: ITS, 2014.

[3] Cho, Young-Sik, and Hanju Cha. "Single-tuned Passive Harmonic Filter Design Considering Variances of Tuning and Quality Factor." Journal of International COuncil on Electrical Engineering, 2011: 3.

[4] Holvik, Jon. "Basic of Dynamic Positioining." Dynamic Positioining Conference, 1998: 1.

[5] Roa, Michael. "Demonstration Of Fault Ride Through Capability For Closed Bus Operation On Dynamic Positioning Vessels." IEEE Journal, 2016.

[6] Rokeberg, Holger. DP Classification. Houston: Marine Technology Society, 1997.

[7] Satrio, Faisal Muhammad, Indra Ranu Kusuma, and Sardono Sarwito. "Designing Passive Harmonic Filter Beacause The Use of Electric Propulsion System with Three Phase Induction Motor on Tanker Ship." International Journal of Marine Engineering Innovation and Research, 2017: 1.

[8] Sumarno, Stefanus Suryo, Ontoseno Penangsang, and Ni Ketut Aryani. "Studi Analisis dan Mitigasi Harmonisa pada PT. Smeen Indonesia Pabrik Aceh." (JURNAL TEKNIK ITS) 5, no. 2 (2016). 